\title{
Cardiac versus Coronary Vasodilator Actions of Isobutylmethylxanthine in Dogs: Comparison with Theophylline
}

\author{
Kenzo TAKAHASHI, Yukio WADA and Norio TAIRA \\ Department of Pharmacology, Tohoku University School of Medicine, \\ Sendai 980, Japan
}

Accepted January 20, 1986

\begin{abstract}
Cardiac and coronary vasodilator effects of isobutylmethylxanthine (IBMX) and theophylline were compared in isolated, blood-perfused papillary muscle, sino-atrial (SA) node and atrioventricular (AV) node preparations of dogs. IBMX (1 $\mathrm{nmol}-1 \mu \mathrm{mol})$ and theophylline $(30 \mathrm{nmol}-10 \mu \mathrm{mol})$ were injected intraarterially. In paced papillary muscle preparations, both agents increased the force of contraction. In spontaneously beating papillary muscle preparations, both agents increased the rate of ventricular automaticity. In SA node preparations, both agents increased sinus rate. In AV node preparations, both agents decreased $A V$ conduction time only when they were injected into the artery supplying the AV node. In all preparations, both agents increased coronary blood flow. However, both agents were not homogeneously effective on these cardiovascular variables, but showed selectivity in the following order: Ventricular muscle contraction $\fallingdotseq$ coronary blood flow $>$ SA nodal automaticity $\fallingdotseq$ AV nodal conduction $>$ ventricular automaticity. These results indicate that IBMX and theophylline have almost an identical profile in their cardiac and coronary vasodilator effects. The two agents were different in that IBMX was 40-50 times as potent as theophylline in producing these effects. Thus, both agents appeared to express their cardiovascular profiles mainly through inhibition of cyclic AMP phosphodiesterase, although theophylline has been claimed to have additional actions.
\end{abstract}

Recently, an intensive search has been carried out to find new non-sympathomimetic and non-glycoside positive inotropic agents (simply called novel positive inotropic agents hereafter) which can replace digitalis. As a result, nearly a dozen agents have been developed such as amrinone (1,2), AR-L 115 BS (sulmazole) (3, 4), MDL $17043(5,6)$, milrinone (7, 8), MDL 19205 (piroximone) (9-11), OPC-8212 (12, 13), UD-CG 115 BS (14), Ro 13-6438 (15, 16), LY175326 (17). APP 201-533 (18, 19), DPI 201-106 (20). Of these agents, except for DPI 201-106 (20), inhibition of cyclic AMP phosphodiesterase (PDE) and a resultant increase in intracellular cyclic AMP in myocardium have been proposed to be involved as a mechanism for the positive inotropic effect, although this may not be the sole mechanism. Indeed, PDE inhibitory activity in crude enzyme or purified enzyme (isozyme III) preparations has been demonstrated for amrinone (21, 22), sulmazole (23-25), MDL $17043(6,25)$, milrinone (7), piroximone (11), OPC-8212 (13), UD-CG 115 BS (14), Ro 13-6438 (16) and APP 201-533 (18). Elevation of intracellular cyclic AMP in myocardium at drug concentrations producing a positive inotropic effect has been demonstrated for amrinone (21, 22), sulmazole (25), MDL 17043 (25), milrinone (7), piroximone (26), OPC-8212 $(13,27)$, UD-CG 115 BS (14), Ro 13-6438 (16) and APP 201-533 (19). Thus, it was of interest to know whether and how these agents are different in cardiovascular profile from classical PDE inhibitors. In a previous article (24), the cardiac vs. coronary vasodilator actions of sulmazole were investigated in comparison with those of theophylline. 3-Isobutyl-1-methylxanthine 
(IBMX) is known to be more specific than theophylline as a PDE inhibitor (28) and has been used as a reference drug in studies dealing with the relation between changes in intracellular cyclic AMP and positive inotropy $(14,21,22,26)$. Nevertheless, little information is available about its detailed cardiac vs. coronary vasodilator actions. The present experiments were attempted to obtain this information using isolated, blood-perfused dog heart preparations with which this type of information has been obtained about theophylline (24), sulmazole (24), OPC8212 (13). MDL 17043 (29) and MDL 19205 (29).

\section{Materials and Methods \\ Preparations}

The preparations described below were obtained from mongrel dogs of either sex weighing 7-12 kg. The animals were anesthetized with sodium pentobarbital $(30 \mathrm{mg} /$ $\mathrm{kg}$, i.v.), given calcium heparin $(500 \mathrm{U} / \mathrm{kg}$, i.v.) and exsanguinated.

Papillary muscle preparation: The papillary muscle preparation was essentially the anterior papillary muscle of the right ventricle taken together with the ventricular septum. The preparation was fixed to a plastic plaque with a hole in which the papillary muscle was fitted at the base. The preparation was perfused through the cannulated anterior septal artery (ASA) with arterial blood from a donor dog at a constant pressure of about $100 \mathrm{mmHg}$ (30). The papillary muscle was preloaded with the weight so as to produce 4-5 g of basal developed tension. The papillary muscle was stimulated with rectangular pulses of about 1.5 times the threshold voltage and $5 \mathrm{msec}$ duration at a rate of 120 stimuli/min through bipolar electrodes placed at the base of the papillary muscle. Tension developed by the papillary muscle was measured isometrically with a strain-gauge transducer (Shinkoh, UL-20GR) In a series of experiments on ventricular automaticity, the papillary muscle was not stimulated, and the rate of automaticity was measured by a cardiotachometer (San-ei, 1321) triggered by bipolar electrograms obtained from the base of the papillary muscle.
SA node preparation: The SA node preparation was essentially the right atrium. The preparation was perfused through the cannulated right coronary artery (RCA) with arterial blood from a donor dog at a constant pressure of about $100 \mathrm{mmHg}$ (31). Sinus rate was measured with a cardiotachometer (San-ei, 1321) triggered by bipolar electrograms obtained from the SA node area.

AV node preparation: The AV node preparation consisted of the right atrium and the ventricular septum. The preparation was perfused through cannulas placed in the RCA, the posterior septal artery (PSA) and the ASA with arterial blood from a donor dog at a constant pressure of about $120 \mathrm{mmHg}$ (32). The right atrium was paced with rectangular pulses of about twice the threshold voltage and $1 \mathrm{msec}$ duration at a rate of 150 stimuli/min through bipolar stimulating electrodes sutured on the endocardium of the crista terminalis. Atrial bipolar electrograms were obtained from near the coronary sinus and ventricular bipolar electrograms from between the AV ring and the anterior papillary muscle of the right ventricle. Both electrograms were fed to an AV interval meter (Data Graph, HN-110), which measured AV conduction time at a resolution of $1 \mathrm{msec}$.

In each preparation, blood flow through its nutrient artery was measured with an electromagnetic flow meter (Nihon Kohden, MF26). All measured variables were recorded on charts with a rectilinear pen-recorder (San-ei, 8S).

Mongrel dogs of either sex weighing 13$27 \mathrm{~kg}$ were used as donors. They were anesthetized with sodium pentobarbital initially at a dose of $30 \mathrm{mg} / \mathrm{kg}$, i.v., and later at supplemental doses when necessary. They were also given calcium heparin initially at a dose of $500 \mathrm{U} / \mathrm{kg}$, i.v., which was followed by doses of $100-200 \mathrm{U} / \mathrm{kg}$, i.v., at hourly intervals.

\section{Drugs}

3- |sobutyl - 1 - methylxanthine (IBMX, Aldrich) and theophylline (Wako) were dissolved in $0.9 \%$ saline. Drug solutions of desired concentrations were injected into the nutrient artery in each preparation in a volume of $30 \mu \mathrm{l}$ over $4 \mathrm{sec}$ with a micro- 
syringe except for the highest doses of IBMX (1 $\mu \mathrm{mol})$ and theophylline $(10 \mu \mathrm{mol})$. The latter doses were injected in a volume of 100 $\mu \mid$ over $10 \mathrm{sec}$. Injections of saline in these volumes had virtually no effect on blood flow and any of the cardiac variables measured. Statistical analysis

Values are expressed in terms of meanst S.E. All changes in cardiac variables and coronary blood flow were expressed as percentages of the respective basal values. Doses that produced a certain amount of changes in cardiac variables or blood flow were determined from dose-response curves fitted by linear regressions and given with confidence limits for 0.95 probability in parentheses.

\section{Results}

Effects on developed tension of the paced papillary muscle and on blood flow through the ASA: In six paced papillary muscle preparations, the basal developed tension was $4.1 \pm 0.2 \mathrm{~g}$ and blood flow through the ASA was $5.2 \pm 0.8 \mathrm{ml} / \mathrm{min}$. A single injection of IBMX (1 $\mathrm{nmol}-1 \mu \mathrm{mol})$ or theophylline (30 nmol-10 $\mu \mathrm{mol})$ into the ASA increased developed tension in a dose-dependent manner (Figs. 1 and 2). With a 10-fold increase in dose, the developed tension increased by about $80 \%$ with IBMX and about $55 \%$ with theophylline. The doses (DTED $50 \%$ ) which produced a $50 \%$ increase in developed tension were 32 [19-55] $\mathrm{nmol}$ for IBMX and 1.3 [0.8-2.5] $\mu \mathrm{mol}$ for theophylline. Based upon DTED 50\%, IBMX was about 40 times as potent as theophylline in producing a positive inotropic effect. Ventricular arrhythmia occurred in two of the six preparations only with the highest dose (1 $\mu \mathrm{mol})$ of IBMX.

IBMX (1 nmol-1 $\mu \mathrm{mol})$ and theophylline (30 nmol-10 $\mu \mathrm{mol}$ ) also increased the ASA flow in a dose-dependent manner (Figs. 1 and 3). A 10-fold increase in dose resulted in about a $39 \%$ increase in ASA flow with IBMX and about a 45\% increase with theophylline. The doses (BFED 50\%) which
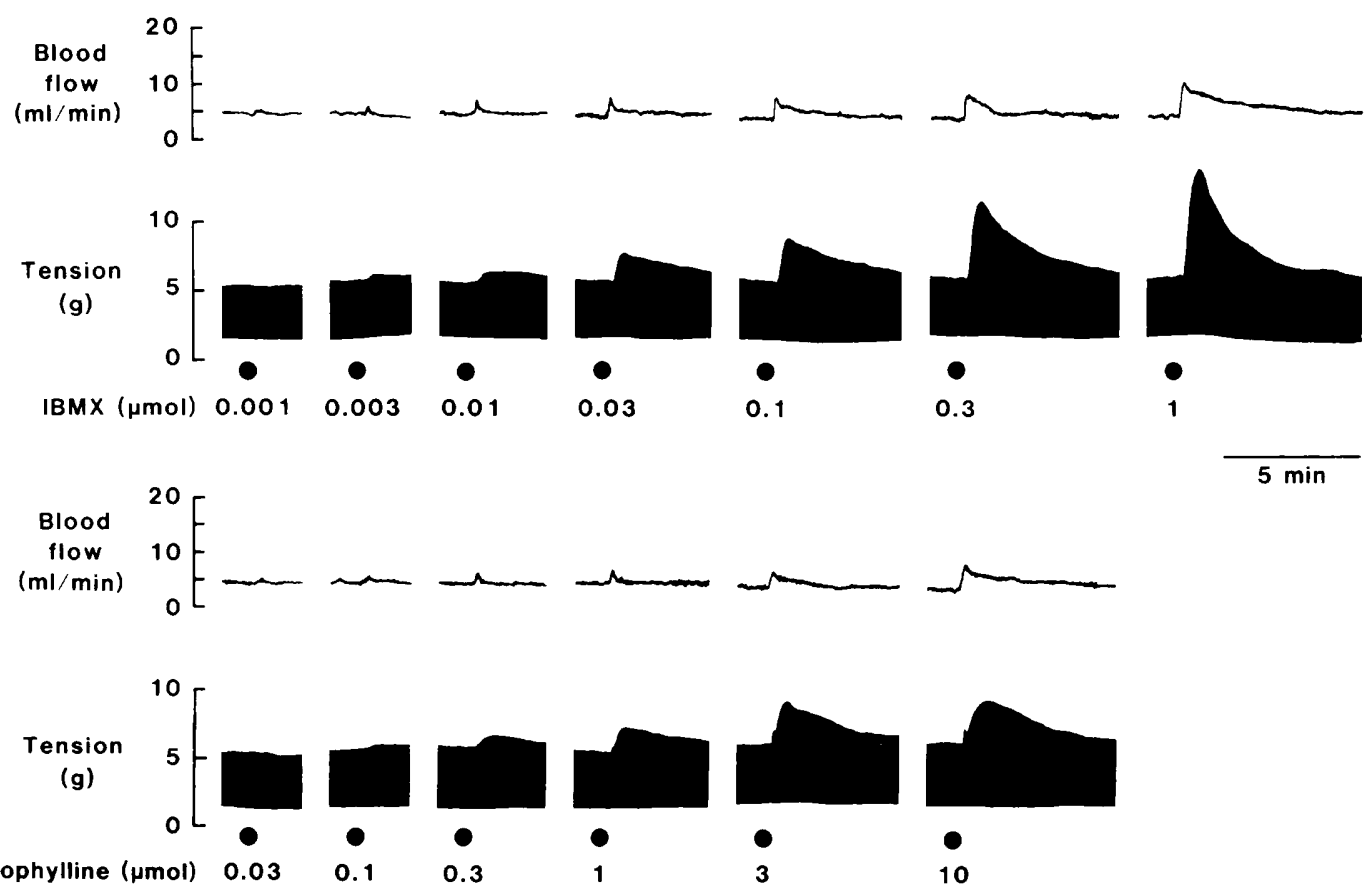

Fig. 1. Effects of IBMX (upper panel) and theophylline (lower panel) injected into the ASA on blood flow through it (upper traces in each panel) and developed tension of the papillary muscle (lower traces in each panel) of an isolated, blood-perfused papillary muscle preparation of the dog. 


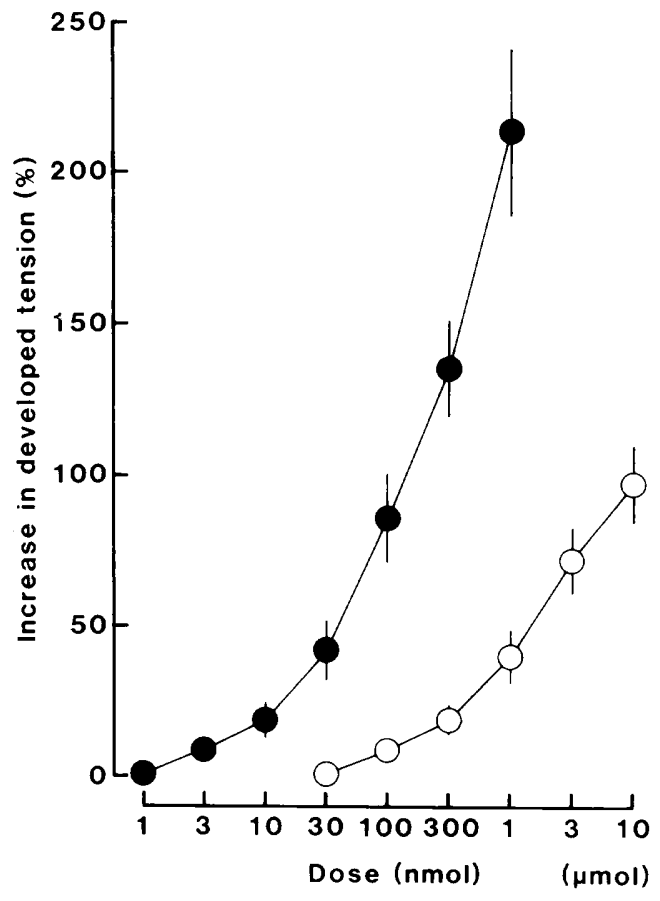

Fig. 2. Dose-response curves to IBMX (closed circles) and theophylline (open circles) for increase in developed tension of the papillary muscle determined in six isolated, blood-perfused papillary muscle preparations of the dog. Both agents were injected into the ASA of the preparations. Data points represent means $\pm S$.E.

produced a $50 \%$ increase in ASA flow were 25 [1-81] nmol for IBMX and 1.3 [0.5-18.5] $\mu \mathrm{mol}$ for theophylline. On the basis of BFED $50 \%$, IBMX was about 50 times as potent as theophylline in producing coronary vasodilatation.

Effects on rate of automaticity and developed tension of the spontaneously beating papillary muscle: Experiments were performed on seven other papillary muscle preparations beating spontaneously. This ventricular automaticity is thought to originate in Purkinje fibers in the ventricular septum. The basal rate was $41 \pm 1$ beats/min and the basal developed tension was $4.3 \pm 0.3 \mathrm{~g}$. Single injections of IBMX (1 $\mathrm{nmol}-1 \mu \mathrm{mol})$ and theophylline $(30 \mathrm{nmol}-10 \mu \mathrm{mol})$ into the ASA increased the rate of automaticity and the developed tension (Figs. 4 and 5). Although developed tension was increased by

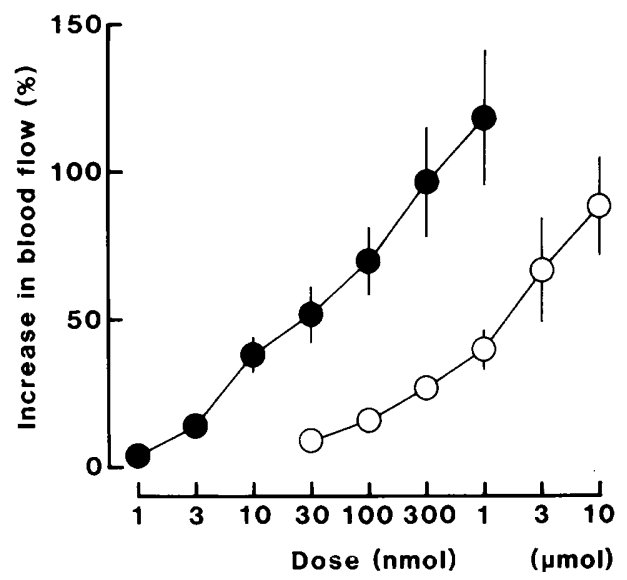

Fig. 3. Dose-response curves to IBMX (closed circles) and theophylline (open circles) for increase in ASA flow determined in six isolated, bloodperfused papillary muscle preparations of the dog. Data points represent means \pm S.E.

each dose of both agents nearly to the same extent as in the paced papillary muscle preparations, the rate of ventricular automaticity was increased only slightly by both agents: at the highest dose, the increase remained about $22 \%$ (about 10 beats $/ \mathrm{min}$ ) for IBMX (1 $\mu \mathrm{mol}$ ) and about 14\% (about 6 beats/min) for theophylline $(10 \mu \mathrm{mol})$. However, ventricular arrhythmia occurred in three of the seven preparations only with the highest dose $(1$ «mol) of IBMX.

Effects on sinus rate and blood flow through the RCA: In six SA node preparations, the basal sinus rate was $101 \pm 3$ beats $/ \mathrm{min}$, and blood flow through the RCA was $2.6 \pm 0.5$ $\mathrm{ml} / \mathrm{min}$. Single injections of IBMX (1 nmol$1 \mu \mathrm{mol}$ ) and theophylline (30 nmol-10 $\mu \mathrm{mol})$ into the RCA produced a dosedependent increase in sinus rate (Figs. 6 and 7 ). The increase in sinus rate produced by a 10 -fold increase in dose was about 34\% for IBMX and about $27 \%$ for theophylline. The doses (SRED 20\%) which produced a $20 \%$ increase in sinus rate were 45 [18-72] nmol for IBMX and 1.8 [1.2-2.5] $\mu \mathrm{mol}$ for theophylline. Based upon SRED 20\%, IBMX was about 40 times as potent as theophylline in producing a positive chronotropic effect. No sinus arrhythmia occurred with any dose examined of either drug. Blood flow through the RCA 

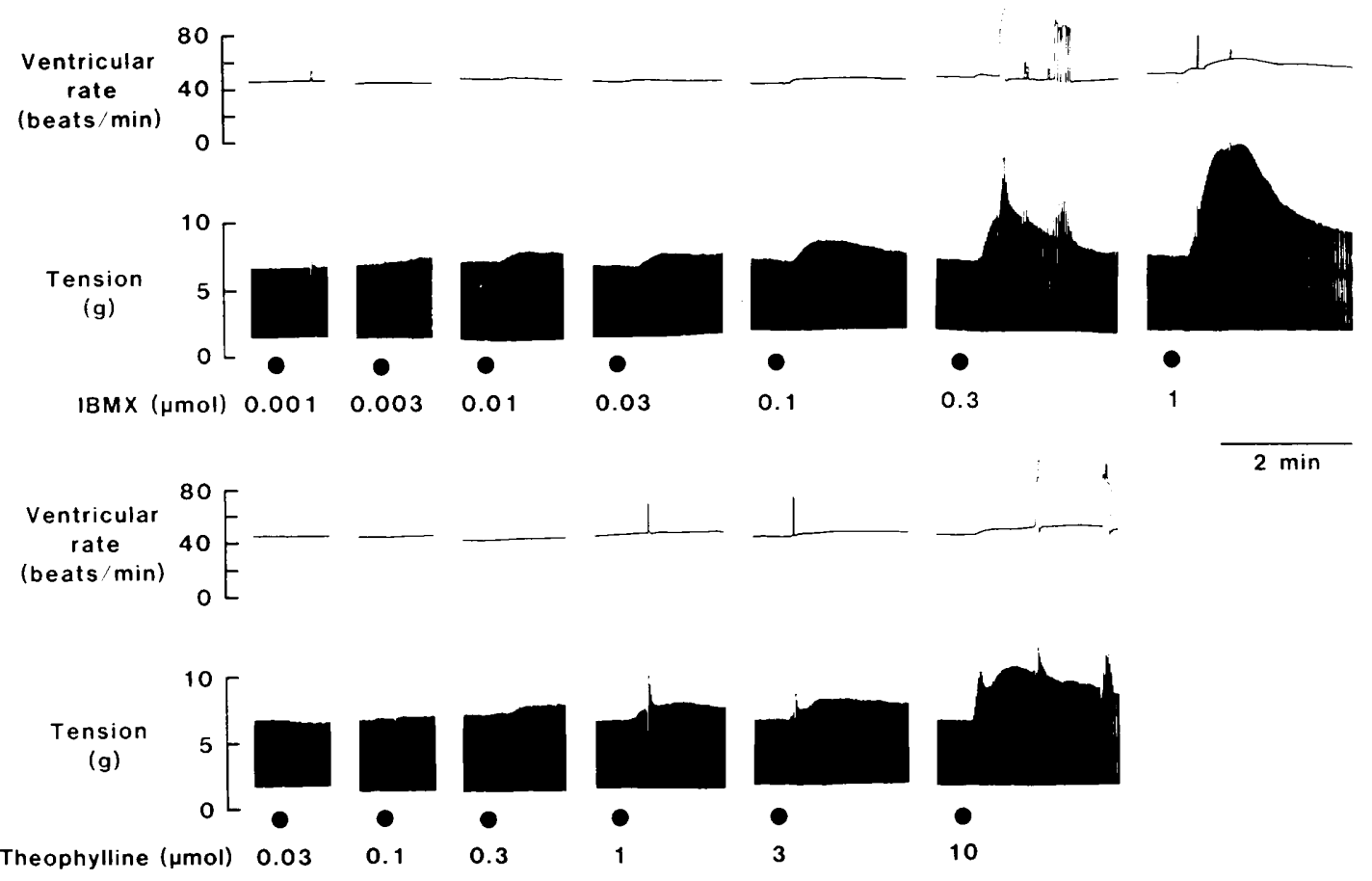

Fig. 4. Effects of IBMX (upper panel) and theophylline (lower panel) injected into the ASA on rate of automaticity (upper traces in each panel) and developed tension (lower traces in each panel) of the papillary muscle in a spontaneously beating papillary muscle preparation of the dog.

was increased by both agents in a dosedependent manner.

Effects on AV nodal and intraventricular conduction and blood flow through the PSA and ASA: In six AV node preparations, the basal AV conduction time was $121 \pm 4 \mathrm{msec}$ at a pacing rate of 150 stimuli/min, and the basal blood flow through the PSA and ASA was $5.4 \pm 0.9$ and $5.0 \pm 0.3 \mathrm{ml} / \mathrm{min}$, respectively. The AV node is predominantly supplied by the PSA, whereas the His-Purkinjeventricular system is supplied by the ASA. Thus, a change in AV conduction time produced by a drug injected into the PSA is ascribable to that of $\mathrm{AV}$ nodal conduction time, whereas a change in AV conduction time produced by a drug injected into the ASA refers to that of intraventricular conduction time. When injected into the PSA. IBMX (1 $\mathrm{nmol}-1 / \mathrm{mol})$ and theophylline (30 nmol-10 $\mu \mathrm{mol}$ ) produced a dose-dependent decrease in AV conduction time (Figs. 8 and $9)$. The decrease in $A V$ conduction time produced by a 10-fold increase in dose was about $12 \%$ for both IBMX and theophylline. The doses (AVCTED 10\%) which produced a $10 \%$ decrease in $\mathrm{AV}$ conduction time were 21 [14-28] nmol for IBMX and 1.1 [0.7-1.6] / mol for theophylline. Based upon AVCTED $10 \%$, IBMX was about 50 times as potent as theophylline in producing a positive dromotropic effect. AV junctional tachycardia or arrhythmia occurred in two of the six preparations only with the highest dose (1 umol) of IBMX. IBMX (1 nmol-1 $\mu \mathrm{mol})$ and theophylline (30 nmol-10 $\mu \mathrm{mol})$, when injected into the ASA, produced virtually no effect on AV conduction time. However, ventricular arrhythmia occurred in two of the six preparations only with the highest dose (1 umol) of IBMX. Both agents produced a dose-dependent increase in blood flow through the PSA or ASA in each preparation.

\section{Discussion}

In the present experiments using isolated, blood-perfused dog heart preparations, both IBMX and theophylline increased the force of 
contraction of ventricular muscle, coronary blood flow, sinus rate and rate of ventricular automaticity, and decreased AV nodal conduction time. In both agents, the positive inotropic and coronary vasodilator effects were more pronounced than other effects. In order to delineate the cardiac and coronary vasodilator profiles of both agents, they are
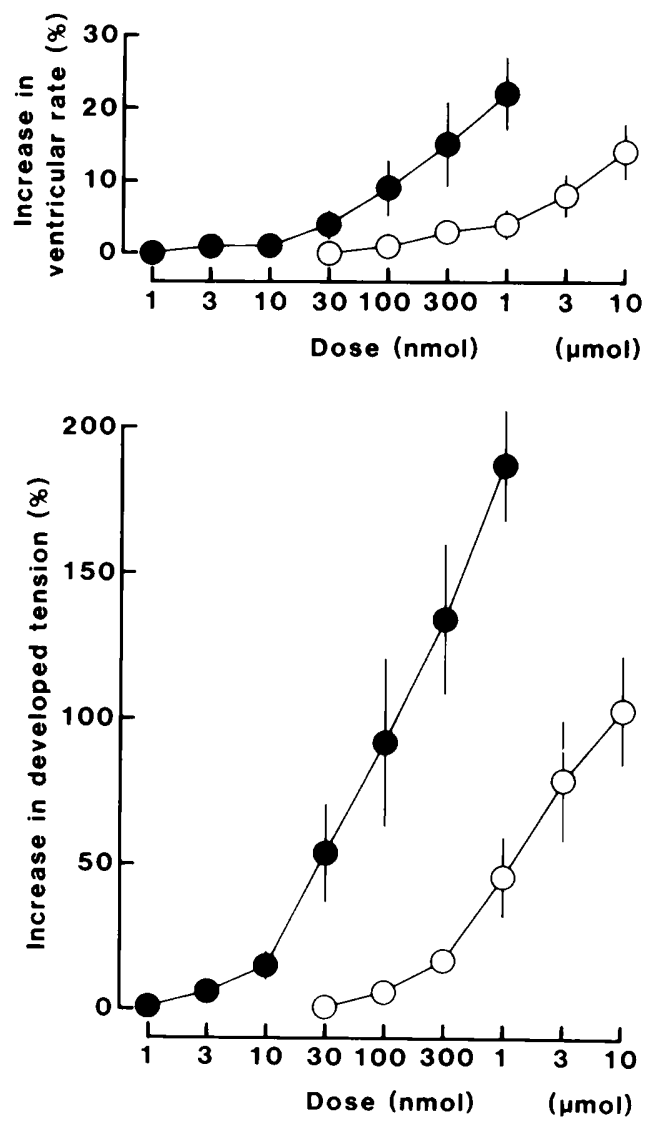

Fig. 5. Dose-response curves to IBMX (closed circles) and theophylline (open circles) for increases in rate of automaticity (upper panel) and developed tension (lower panel) of the papillary muscle determined in seven isolated, blood-perfused papillary muscle preparations of the dog. Both agents were injected into the ASA of the preparations. Data points represent means \pm S.E.

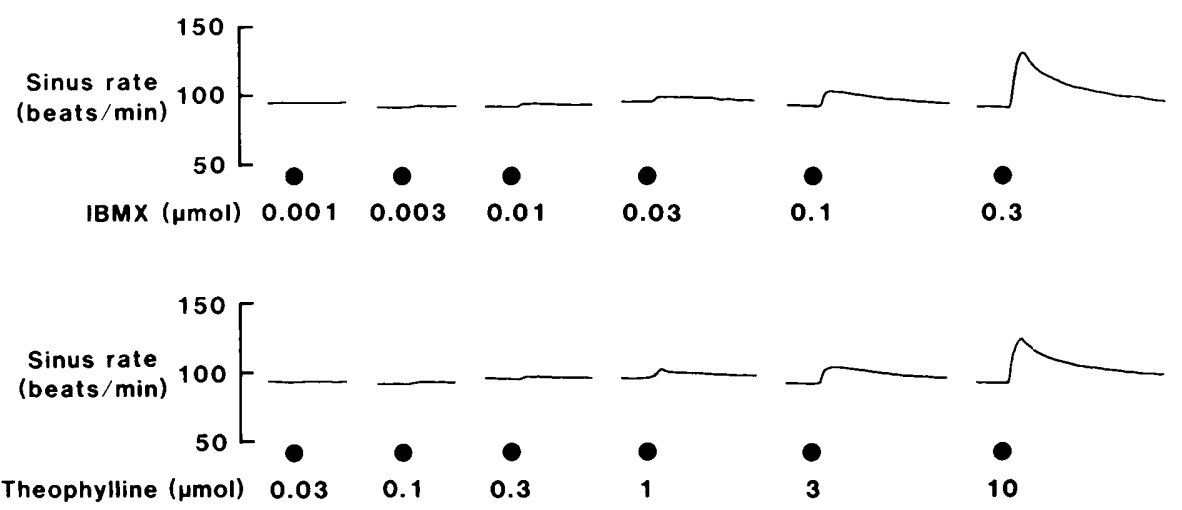

Fig. 6. Effects of IBMX (upper panel) and theophylline (lower panel) injected into the RCA on sinus rate of an isolated, blood-perfused SA node preparation of the dog. 


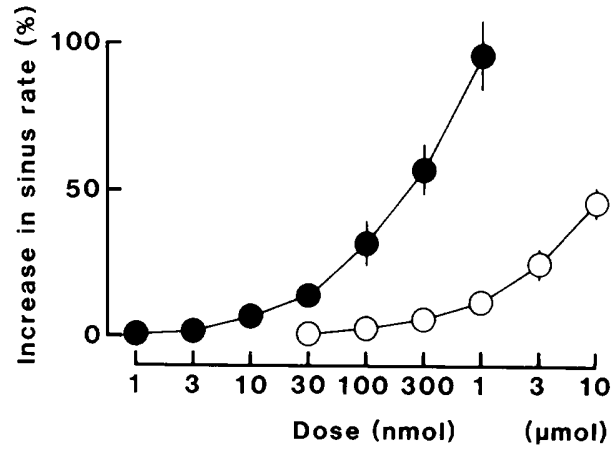

Fig. 7. Dose-response curves to IBMX (closed circles) and theophylline (open circles) for increase in sinus rate determined in six isolated, bloodperfused SA node preparations of the dog. Both agents were injected into the RCA. Data points represent means \pm S.E.

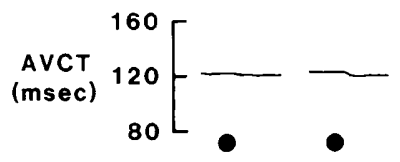

IBMX ( $\mu \mathrm{mol}) 0.001$
0.003

0.01

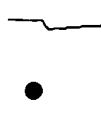

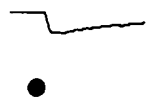

0.03

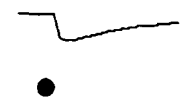

0.1

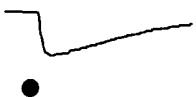

0.3

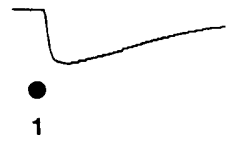

$5 \mathrm{~min}$

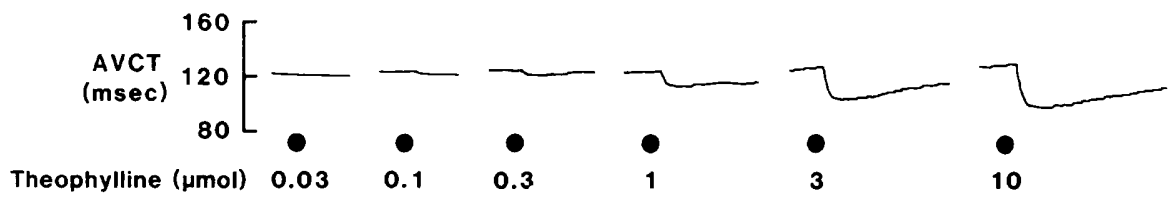

Fig. 8. Effects of IBMX (upper panel) and theophylline (lower panel) injected irito the PSA on AV conduction time (AVCT) in an isolated, blood-perfused AV node preparation of the dog.

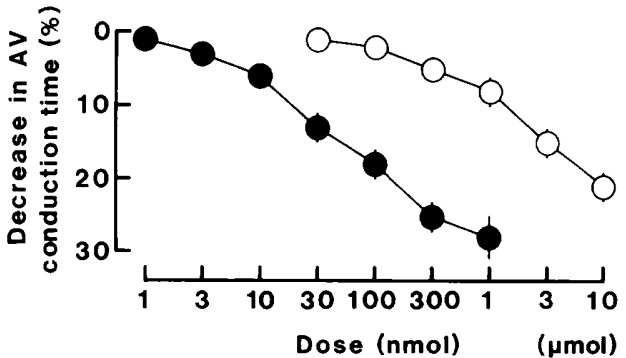

Fig. 9. Dose-response curves to IBMX (closed circles) and theophylline (open circles) for decrease in $\mathrm{AV}$ conduction time determined in six isolated. blood-perfused AV node preparations of the dog. Both agents were injected into the PSA. Data points represent means \pm S.E.

diagramatically expressed in Fig. 10 as previously described $(13,29)$. In this figure, changes in sinus rate, AV conduction time and blood flow through the ASA caused by the dose which produced a $50 \%$ increase in developed tension of the papillary muscle are shown as percentages of the respective basal values on a pentagonal plan. Changes in ventricular rate alone were expressed as percentages of the basal sinus rate, because any increase in ventricular rate does not lead to ventricular tachycardia unless the increased ventricular rate exceeds the sinus rate. Since blood flow through the nutrient arteries of the respective preparation was different, percentage changes in various variables were determined from doseresponse curves at flow-matched doses. As seen in this figure, the order of effectiveness of both agents on these cardiovascular variables was as follows: contraction of ventricular muscle $\fallingdotseq$ coronary blood flow $>$ sinus rate $\fallingdotseq \mathrm{AV}$ nodal conducation time $>$ ventricular rate. Thus, it can be concluded that both agents have almost an identical profile in their cardiac and coronary vasodilator effects, although IBMX was 4050 times as potent as theophylline in pro- 

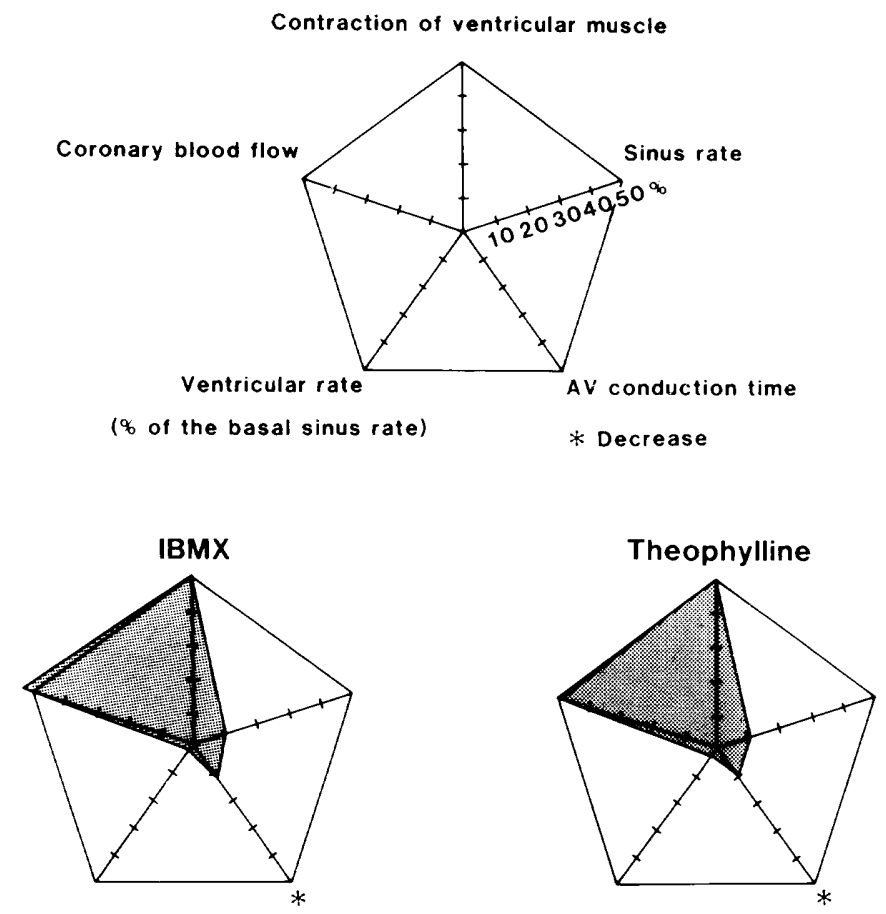

Fig. 10. Cardiovascular profiles of IBMX and theophylline delineated by use of isolated, blood-perfused dog heart preparations. On pentagonal plans are plotted changes in sinus rate, AV conduction time and coronary blood flow as percentages of the respective basal values at the dose which produced a $50 \%$ increase in the force of contraction of ventricular muscle. Changes in ventricular rate alone are expressed as percentages of the basal sinus rate, because any increase in ventricular rate will not lead to ventricular tachycardia as far as ventricular rate remains lower than sinus rate. Changes without an asterisk are increases.

ducing these effects.

Theophylline has long been used as a reference PDE inhibitor. However, it has also been suggested that theophylline has additional actions on the movement of calcium $(33,34)$. On the other hand, IBMX has been claimed to be a more specific PDE inhibitor with minimal additional actions than other methylxanthines like theophylline (28). Therefore, it was expected that there would be some difference in cardiovascular profile between the two agents. In the present experiments, however, only the slope of the dose-response curve to $\mathrm{BM} \mathrm{BX}$ for an increase in developed tension was seeper than that to theophylline; the increase in developed tension produced by a 10 -fold increase in dose was about $80 \%$ for IBMX against about $55 \%$ for theophylline. The less effectiveness of theophylline in increasing developed tension seen particularly with higher doses might be due to its additional actions on the movement of calcium so as to blunt an increase in developed tension by PDE inhibition. Close resemblance of IBMX to theophylline in cardiovascular profile disclosed with their medium doses in the present experiments (Fig. 10) indicates that up to medium doses, both agents would behave mainly as PDE inhibitors and that additional actions of theophylline do not contribute much to expression of its cardiovascular profile.

As described in the introduction section, most of the novel positive inotropic agents appear to involve more or less PDE inhibition and a resultant increase in intracellular cyclic AMP as a main mechanism of positive inotropy. Since the prototype PDE inhibitor theophylline increases heart rate and 
myocardial oxygen consumption, it has been a major concern in the development of novel positive inotropic agents to screen an agent which has a high degree of separation of the positive inotropic from the positive chronotropic effect. As seen in Fig. 10, IBMX increased sinus rate only a little more than $10 \%$ at the dose that produced a $50 \%$ increase in the force of contraction of ventricular muscle, and theophylline exhibited similar behavior. This is a sizable force-rate separation. A similar degree of force-rate separation has been seen with sulmazole (24), MDL 17043 (29), piroximone (29). amrinone and milrinone ( $Y$. Sato et al., unpublished data) in isolated, bloodperfused dog heart preparations. OPC-8212 alone is an exception; it tended to produce a negative chronotropic effect in the isolated, blood-perfused SA node preparation of the dog (13). Thus, as far as the force-rate separation is concerned, most of the novel positive inotropic agents are scarcely discernible from the prototype PDE inhibitors.

IBMX and theophylline were nearly as potent in producing coronary vasodilatation as in causing positive inotropy. Unlike the prototype PDE inhibitors, none of the novel positive inotropic agents are equally coronary vasodilatory and positive inotropic. For example, amrinone is more potent in producing coronary vasodilatation than in causing positive inotropy ( $Y$. Sato et al., unpublished data), whereas sulmazole (24), MDL 17043 (29) and piroximone (29) are more positive inotropic than coronary vasodilatory. OPC-8212 scarcely produces coronary vasodilatation (13). Such differences in cardiovascular profiles among novel positive inotropic agents suggest that varied actions additional to their PDE inhibitory activities play an important role in displaying their own cardiovascular profiles. Further experiments are required to elucidate their mechanisms of cardiovascular action including the positive inotropic one.

\section{References}

1 Farah, A.E. and Alousi, A.A.: New cardiotonic agents: A search for digitalis substitute. Life Sci. 22, 1139-1148 (1978)

2 Alousi, A.A., Farah, A.E., Lesher, G.Y. and Opalka, C.J., Jr.: Cardiotonic activity of
amrinone-Win 40680 [5-amino-3,4'-bipyridin$6(1 \mathrm{H})$-one]. Circ. Res. 45, 666-677 (1979)

3 Diederen, W. and Kadatz, R.: Comparative cardiovascular effects of three benzimidazole derivatives, AR-L 57 BS, AR-L 100 BS, and AR-L 115 BS. Arzneimittelforsch. 31, 141-146 (1981)

4 Diederen, W. and Kadatz, R.: Effects of AR-L 115 BS, a new cardiotonic compound, on cardiac contractility, heart rate and blood pressure in anaesthetized and conscious animals. Arzneimittelforsch. 31, 146-150 (1981)

5 Dage, R.C., Roebel, L.E., Hsieh, C.P., Weiner, D.L. and Woodward, J.K.: Cardiovascular properties of a new cardiotonic agent: MDL 17.043 (1,3-dihydro-4-methyl-5-[4-(methylthio)-benzoyl]-2H-imidazol-2-one). J. Cardiovasc. Pharmacol. 4, 500-508 (1982)

6 Kariya, T., Wille, L.J. and Dage, R.C.: Biochemical studies on the mechanism of cardiotonic activity of MDL 17,043. J. Cardiovasc. Pharmacol. 4, 509-514 (1982)

7 Alousi, A.A., Canter, J.M., Montenaro, M.J., Fort, D.J. and Ferrari, R.A.: Cardiotonic activity of milrinone, a new and potent cardiac bipyridine, on the normal and failing heart of experimental animals. J. Cardiovasc. Pharmacol. 5, 792-803 (1983)

8 Alousi, A.A., Stankus, G.P., Stuart, J.C. and Walton, L.H.: Characterization of the cardiotonic effects of milrinone, a new and potent cardiac bipyridine, on isolated tissues from several animal species. J. Cardiovasc. Pharmacol. 5, 804-811 (1983)

9 Dage, R.C., Roebel, L.E., Hsieh, C.P. and Woodward, J.K.: Cardiovascular properties of a new cardiotonic agent, MDL 19205. J. Cardiovasc. Pharmacol. 6, 35-42 (1984)

10 Roebel, L.E., Dage, R.C., Cheng, H.C. and Woodward, J.K.: In vitro and in vivo assessment of the cardiovascular effects of the cardiotonic drug MDL 19205. J. Cardiovasc. Pharmacol. 6, 43-49 (1984)

11 Kariya, T., Wille, L.J. and Dage, R.C.: Studies on the mechanism of the cardiotonic activity of MDL 19205: Effects on several biochemical systems. J. Cardiovasc. Pharmacol. 6, 50-55 (1984)

12 Yamashita, S., Hosokawa, T., Kojima, M., Mori, $\mathrm{T}$. and Yabuuchi, Y.: In vitro and in vivo studies of 3,4-dihydro-6-[4-(3,4-dimethoxybenzoyl)-1piperazinyl]-2(1H) -quinolinone (OPC-8212), a novel positive inotropic drug, in various animals. Arzneimittelforsch. 34, 342-346 (1984)

13 Taira, N., Endoh, M., lijima, T., Satoh, K., Yanagisawa, T., Yamashita, S., Maruyama, M., 
Kawada, M., Morita, T. and Wada, Y.: Mode and mechanism of action of 3,4-dihydro-6-[4(3.4 - dimethoxybenzoyl) - 1 - piperazinyl] - $2(1 \mathrm{H})$ quinolinone (OPC-8212), a novel positive inotropic drug, on the dog heart. Arzneimittelforsch. 34, 347-355 (1984)

14 Honerjäger, P., Heiss, A., Schäfer-Korting, M., Schönsteiner, G. and Reiter, M.: UD-CG 115-a cardiotonic pyridazinone which elevates cyclic AMP and prolongs the action potential in guineapig papillary muscle. Naunyn Schmiedebergs Arch. Pharmacol. 325, 259-269 (1984)

15 Eigenmann, R., Gerold, M. and Holck, M.: Cardiovascular profile of Ro 13-6438, a novel positive inotropic agent with vasodilating properties. J. Cardiovasc. Pharmacol. 6, 511-519 (1984)

16 Holck, M., Thorens, S., Muggli, R. and Eigenmann, R.: Studies on the mechanism of positive inotroic activity of Ro 13-6438, a structurally novel cardiotonic agent with vasodilating properties. J. Cardiovasc. Pharmacol. 6, 520-530 (1984)

17 Hayes, J.S., Pollock, G.D., Wilson, H., Bowling, N. and Robertson, D.W.: Pharmacology of LY175326: A potent cardiotonic agent with vasodilator activities. J. Pharmacol. Exp. Ther. 233, 318-326 (1985)

18 Salzmann, R., Bormann, G., Herzig, J.W., Markstein, R. and Scholtysik, G.: Pharmacological actions of APP 201-533, a novel cardiotonic agent. J. Cardiovasc. Pharmacol. 7, 588-596 (1985)

19 Scholtysik, G., Honerjäger, P., Markstein, R. and Bormann, G.: Positive inotropic and electrophysiological effects of APP 201-533 can be explained by an increase of cardiac cyclic AMP. J. Cardiovasc. Pharmacol. 7, 597-603 (1985)

20 Scholtysik, G., Salzmann, R., Berthold, R., Herzig, J.W., Quast, U. and Markstein, R.: DPI 201-106, a novel cardioactive agent. Combination of CAMP-independent positive inotropic. negative chronotropic, action potential prolonging and coronary dilatory properties. Naunyn Schmiedebergs Arch. Pharmacol. 329, 316-325 (1985)

21 Honerjäger, P., Schäfer-Korting, M. and Reiter, M.: Involvement of cyclic AMP in the direct inotropic action of amrinone. Biochemical and functional evidence. Naunyn Schmiedebergs Arch. Pharmacol. 318, 112-120 (1981)

22 Endoh, M., Yamashita, S. and Taira, N.: Positive inotropic effect of amrinone in relation to cyclic nucleotide metabolism in the canine ventricular muscle. J. Pharmacol. Exp. Ther. 221, 775-783 (1982)
23 Diederen, W. and Weisenberger, H.: Studies on the mechanism of the positive-inotropic action of AR-L 115 BS, a new cardiotonic drug. Arzneimittelforsch. 31, 177-182 (1981)

24 Morita, T., Satoh, K. and Taira, N.: Comparison of the cardiovascular and biochemical profiles of a new positive inotropic drug, AR-L 115 BS. with those of theophylline. Japan. Heart J. 25, 447-460 (1984)

25 Endoh, M., Yanagisawa, T., Morita, T. and Taira, N.: Differential effects of sulmazole (AR-L 115 BS) on contractile force and cyclic AMP levels in canine ventricular muscle: Comparison with MDL 17,043. J. Pharmacol. Exp. Ther. 234, 267-273 (1985)

26 Cheng, H.C., Kariya, T., Gleason, E.M. and Dage, R.C.: Studies on the mechanism of the positive inotropic effect of piroximone in cat papillary muscle. J. Cardiovasc. Pharmacol. 7. 747-752 (1985)

27 Yanagisawa, T., Endoh, M. and Taira, N.: Involvement of cyclic AMP in the positive inotropic effect of OPC-8212, a new cardiotonic agent, on the canine ventricular muscle. Japan. J. Pharmacol. 36, 379-388 (1984)

28 Korth, M.: Effects of several phosphodiesteraseinhibitors on guinea-pig myocardium. Naunyn Schmiedebergs Arch. Pharmacol. 302, 77-86 (1978)

29 Wada, Y. and Taira, N.: Comparative study of MDL 17043 and MDL 19205, new positive inotropic agents, by use of isolated, bloodperfused dog-heart preparations. Heart and Vessels 2 (1986) (in press)

30 Endoh, M. and Hashimoto, K.: Pharmacological evidence of autonomic nerve activities in canine papillary muscle. Am. J. Physiol. 218, 1459 1463 (1970)

31 Kubota, K. and Hashimoto, K.: Selective stimulation of the parasympathetic preganglionic nerve fibres in the excised and blood-perfused SA node preparation of the dog. Naunyn Schmiedebergs Arch. Pharmacol. 278, 135-150 (1973)

32 Hashimoto, K., lijima, T., Hashimoto, K. and Taira, N.: The isolated and cross-circulated AV node preparation of the dog. Tohoku J. Exp. Med. 107, 263-275 (1972)

33 Tsien, R.W.: Cyclic AMP and contractile activity in heart. Adv. Cyclic Nucleotide Res. 8, 363-420 (1977)

34 Endoh, M., lijima, T. and Motomura, S.: Inhibition by theophylline of the early component of canine ventricular contraction. Am. J. Physiol. 242, H349-H358 (1982) 